\title{
Thermal Distortion Tests of Aluminum and Stainless Steel Plates \\ and Stainless Steel Plates
}

E. Bielick, 'T. Fornek", H. Spinka and D. Underwood

OCT 191833

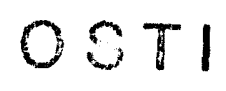

High Energy Physics Division

Argonne National Laboratory

Argonne, Illinois 60439

25 June 1993

An important upgrade to the STAR detector at the Brookhaven National Laboratory RHIC accelerator will be an electromagnetic calorimeter. One design being considered for this calorimeter involves cast lead modules covering $\Delta \phi=6^{\circ}$ and $0 \leq|\eta| \leq 1$. These modules would consist of alternating layers of lead (approximately $5 \mathrm{~mm}$ thick) and sheets of plastic scintillator. The gaps for scintillator between the layers of lead would be created by parallel aluminum plates of thickness $\simeq 6.6 \mathrm{~mm}=0.260$ " in the mold for the modules. These plates would need to be machined or ground to be reasonably flat, perhaps to \pm 0.003 ", and of uniform tr: 'ness from plate to plate. These requirements are imposed by the need to remove the plates from the casting after cooling, and to have good uniformity of the lead layer thickness, which gives good performance for the modules as a calorimeter. Aluminum was chosen for the plates because of its high coefficient of thermal expansion.

An important cost in this calorimeter design is associated with the machining or grinding of the plates to proper thickness and flatness. In most cost estimates, it has been assumed that the mold parts could be used many (typically $\geq 20$ ) times. This note describes a simple test which was conducted to investigate possible distortions in the plates after repeated heating to temperatures at which the lead would be poured "E. Bielick and T. Fornek are on loan from Argonne's Engineering Physics
Division. 
into the mold $\left(\approx 800^{\circ} \mathrm{F}\right)$ and cooling.

Tests were performed on eight different plates simultaneously. The plates consisted of pairs of type 6061-T6 and 1100 aluminum and type 304 and 316 stainless steel. One plate of each pair was ground and the other was machined (see Fig. 1). The plates were labeled. Nine spots at which measurements of distortion were made were also labeled; see Fig. 2. A variety of plate materials were tried in an attempt to compare distortions.

The plate distortion was measured with a dial indicator at the nine labeled points on each plate. The plates were placed on a flat granite surface, and the dial indicator was zeroed at point $A$. The height of each of the other eight points was then measured (see Fig. 3). Each of the plates was measured before any heating, and again after various heating tests.

The plates were stacked horizontally on spacers, as shown in Figs. 4-6, to allow the heated air to circulate to all the plate surfaces. The spacers were approximately located beneath the measured points. Originally it had been planned to heat the plates while they were vertical, but problems with the oven prevented this. Different plates were placed on top of the stack for different heating tests.

The oven is shown in Figs. 6 and 7. The temperature was not accurately controlled. Temperature sticks (melting points $\sim 750^{\circ} \mathrm{F}$ and $800^{\circ} \mathrm{F}$ ) were used to confirm that the temperature of the top plate was slightly over $800^{\circ} \mathrm{F}$. The approximate plate temperature during heating was $800^{\circ} \mathrm{F} \pm 50^{\circ} \mathrm{F}$, and this same approximate temperature range was used for all tests. For most of these tests, the oven was turned on at 9:00 a.m. and off 2:30 p.m. Then the oven door was opened, and a fan blew room temperature air into the oven. The next morning, the plates were removed from the oven and measured for distortion. Thereafter, the process was repeated. 
The plates were heated on May 20, 24, 25, 26, 27, 28 and June 1, 2 and measured on May 19 (preheat), 21, 25, 26 and June 3. Thus, the thermal cycling occurred once for each of the first three measurements and five times for the last measurement. Note that the oven temperature controller, the dial indicator used for the distortion measurements, the certification of materials, and the general method of measuring were not calibrated and/or requested and/or controlled. Nevertheless, important information could be derived from this simple test.

The results of the distortion measurements for each of the eight plates are plotted in Figs. 8-15. The same horizontal and vertical scales and the same symbols are used for all plots. The tests indicate that type 304 stainless steel with ground surfaces would be the most stable of all the materials tested (see Fig. 8), followed by type 316 stainless steel with ground surfaces (Fig. 10). All other plates had considerably larger distortions. Usually the distortion at a particular point on a plate did not continue to grow in the same direction as a function of time. Also, except for the type 316 stainless steel with machined surfaces (Fig. 11), the distortions did not seem to correspond to a single large change after the first heating, followed by very small changes thereafter.

The postheat distortion measurements were all made by the same machinist. Preheat measurements were made by another. An upper limit to the measurement uncertainty can be estimated from the data in Fig. 8, assuming no changes due to heating. The average standard deviation for points B-K corresponds to $\pm 0.0007 "$ ". A reasonable assumption is that this same uncertainty applies to all plates. Thus, the large changes seen for most other plates are real and do not correspond to measurement errors. 
After this series of tests, the 3/16" x 1/2" 6061-T6 aluminum spacers were found to bend very easily; thy had lost their temper. This fact may present problems of stripped threads in aluminum plates used for a calorimeter mold. Further tests of distortions of the thermally cycled plates due to nonuniform loads or dropping onto hard surfaces would be advisable.

The conclusions from this simple test are:

1) Type 1100 and 6061-T6 aluminum plates may suffer considerable distortions $(\geq 0.01 ")$ due to heating by molten lead in a mold. Careful measurements of the flatness of these plates would need to be performed after each casting before reusing these plates. It is not clear that the same plates could be used for even 20 castings, as has been assumed previously. Annealing of the aluminum plates could cause handling problems.

2) Ground surfaces on the plates seem to result in smaller distortions upon thermal cycling to $800^{\circ} \mathrm{F} \pm 50^{\circ} \mathrm{F}$ than machined surfaces for all materials tested.

3) Type 304 stainless steel plates with ground surfaces would be expected to suffer only small distortions due to heating by molten lead in a mold.

4) Repeating these tests with better controls or measurements of temperatures, materials, and distortions with vertical plates may be beneficial to groups considering the use of cast lead technology for the construction of calorimeters. 


\section{Acknowledgments}

This work was supported by the U.S. Department of Energy, Division of High Energy Physics, Contract W-31-109-ENG-38 and by R\&D funding for the RHIC project. 
Fig. 1. Schematic diagram showing dimensions of the plates and tolerances, as well as the materials and method of finishing the surfaces.

Fig. 2. Photograph of a 6061-T6 plate with machined surfaces resting on the flat granite table.

Fig. 3. Photograph of the dial indicator measuring the 6061-T6 plate at position A.

Fig. 4. Photograph of the stacked horizontally on the granite table.

Fig. 5. Photograph of plates stacked horizontally on the granite table.

Fig. 6. Photograph of plates stacked horizontally in the oven.

Fig. 7. Photograph of the oven used to heat the plates. Note the uncalibrated meter to register the temperature.

Plots of the dial indicator reading as a function of position for the five distortion measurements.

Fig. 8. Type 304 stainless steel with ground surfaces.

Fig. 9. Type 301 stainless steel with machined surfaces.

Fig. 10. Type 316 stainless steel with ground surfaces.

Fig. 11. Type 316 stainless steel with machined surfaces.

Fig. 12. Type 1100 aluminum with ground surfaces.

Fig. 13. Type 1100 aluminum with machined surfaces.

Fig. 14. Type 6061-T6 aluminum with ground surfaces.

Fig. 15. Type 6061-T6 aluminum with machined surfaces. 


\begin{tabular}{|l|c|c|c|}
\cline { 2 - 4 } \multicolumn{1}{c|}{} & \multicolumn{2}{c|}{ BITH SIDES } & \multicolumn{1}{c|}{} \\
\hline MAT'L. & GRIND & MACHINE & ND. REQ'D. \\
\hline $\begin{array}{l}\text { G061-TG } \\
\text { ALUM. }\end{array}$ & $X$ & & 1 \\
\cline { 2 - 4 } 1100 ALUM. & $X$ & $X$ & 1 \\
\hline 304 SST & $X$ & $X$ & 1 \\
\hline \multirow{2}{*}{316 SST } & & $X$ & 1 \\
\cline { 2 - 4 } & & $X$ & 1 \\
\hline
\end{tabular}

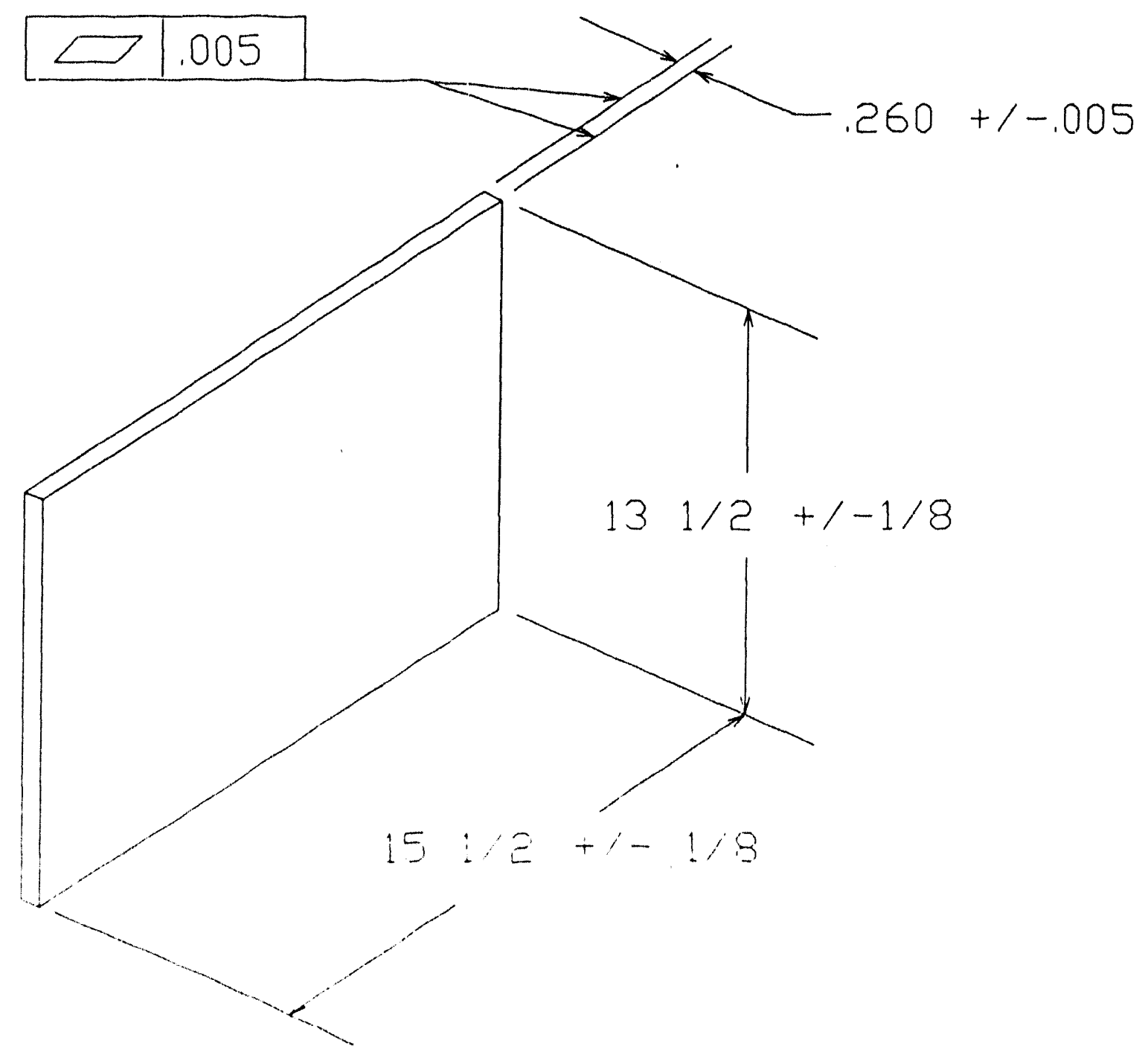

Figure 1. Schematic diagram showing dimensions of the plates, as well as the materials and method of finishing the surfaces. 


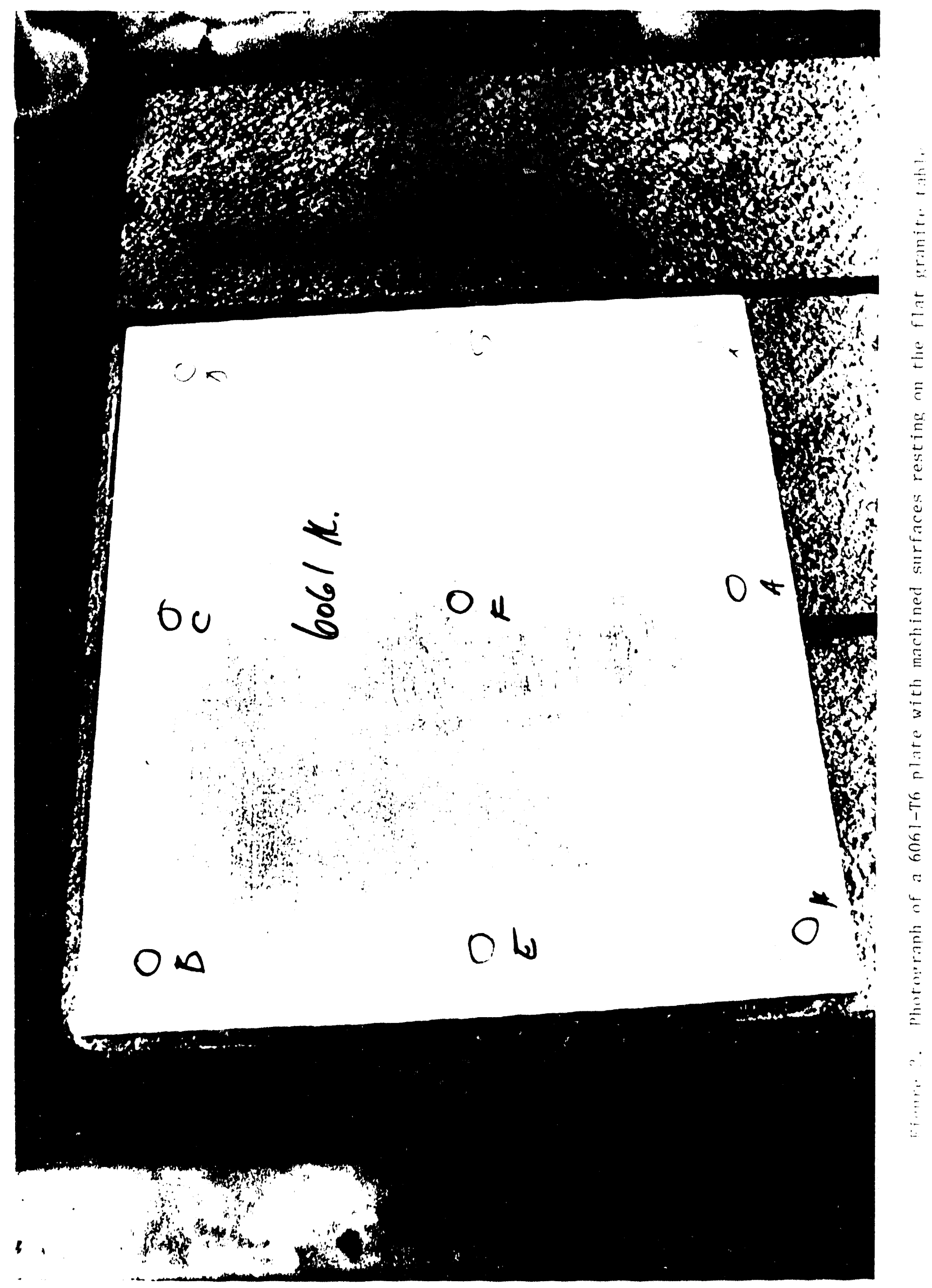




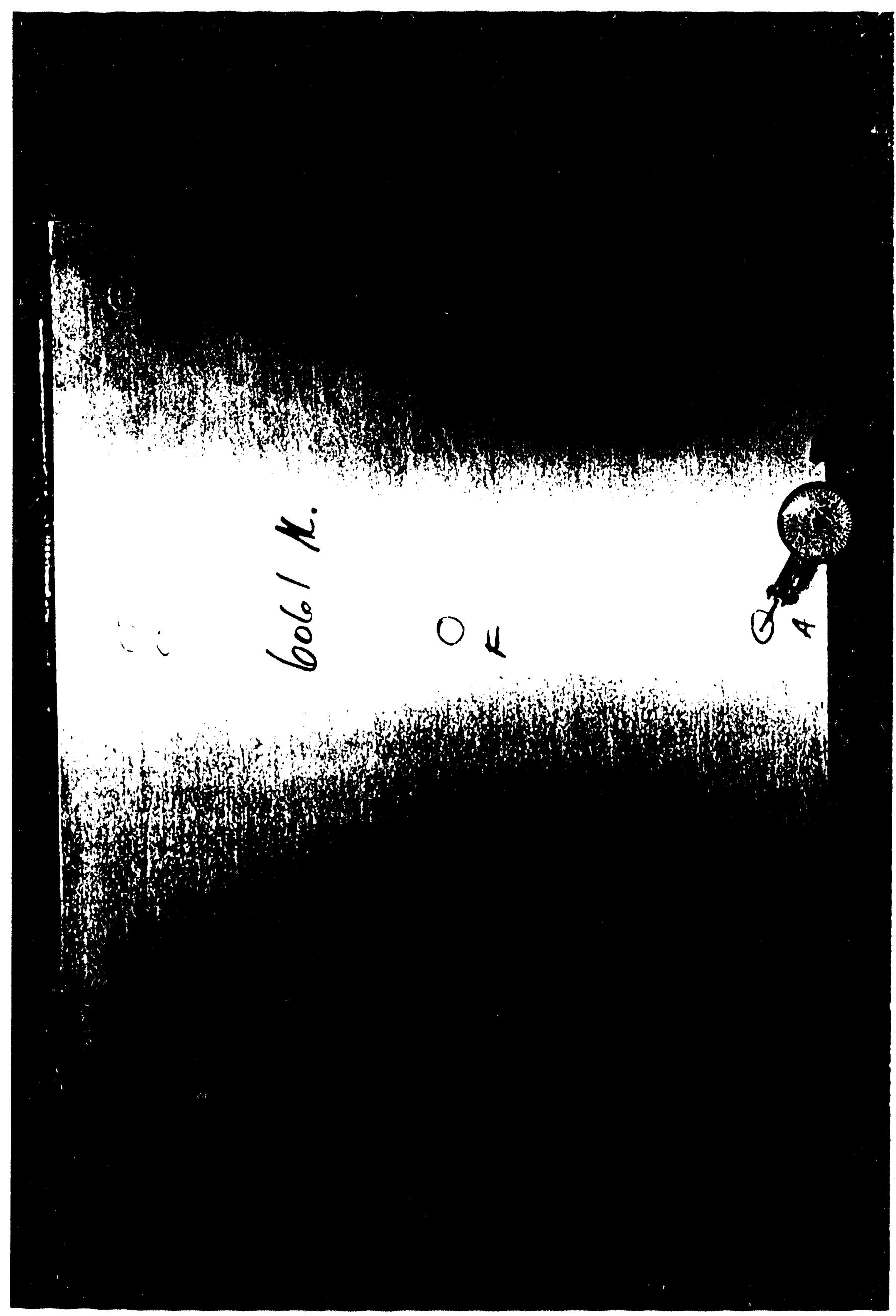




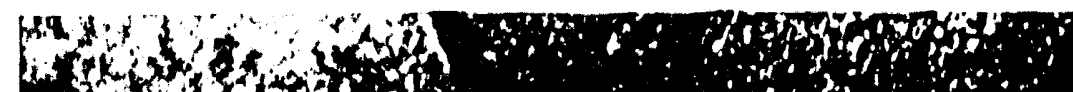

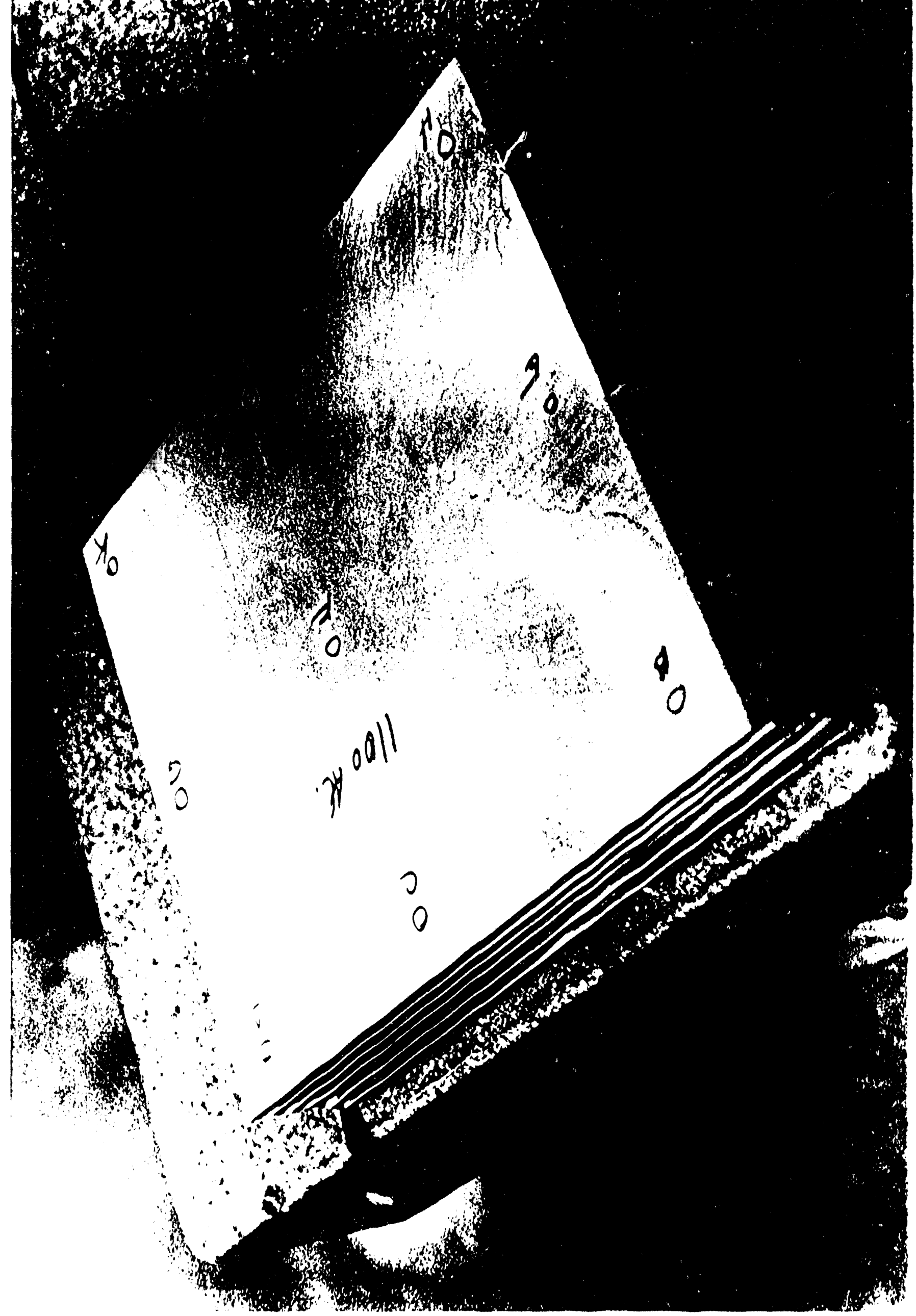




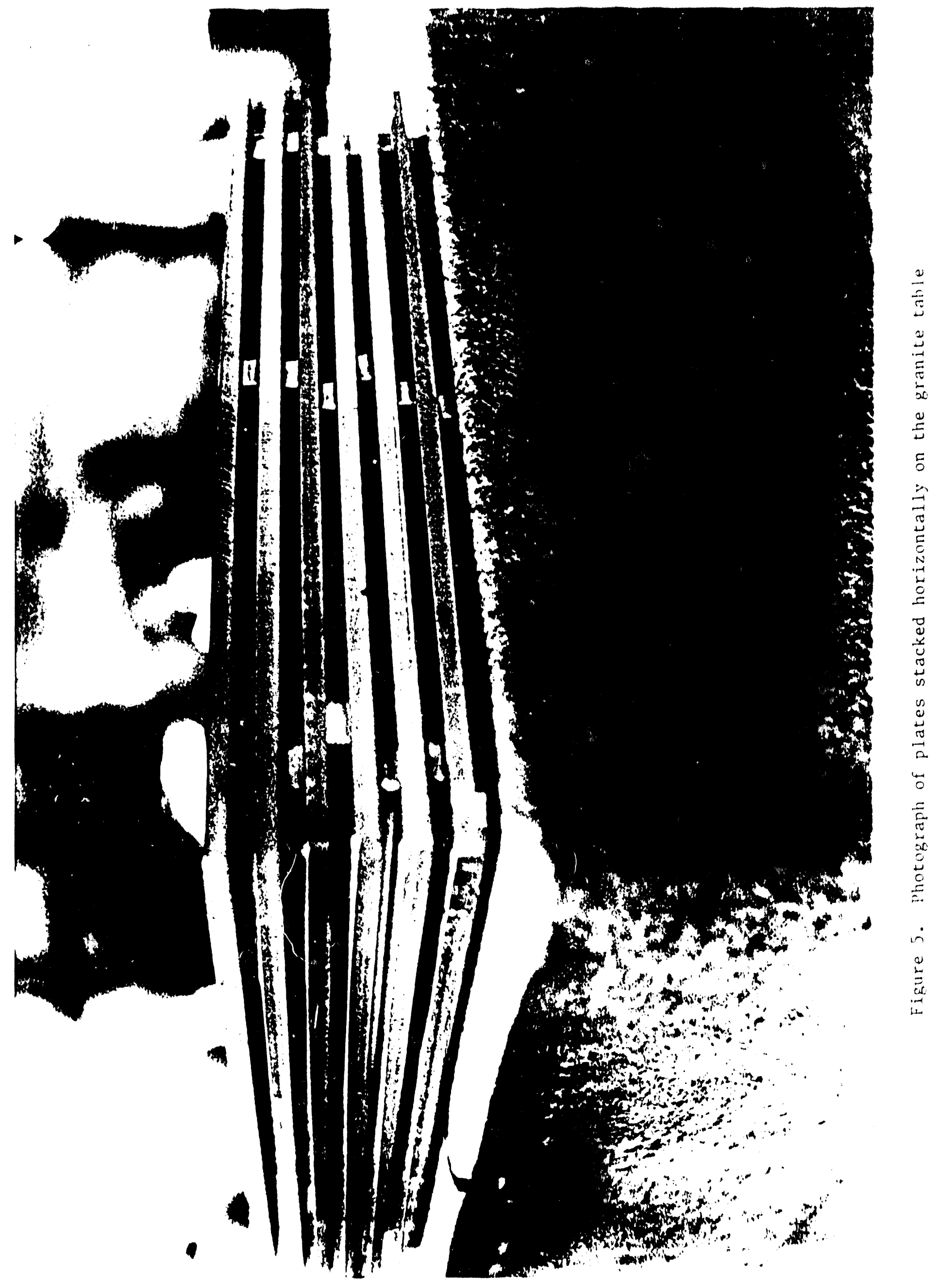




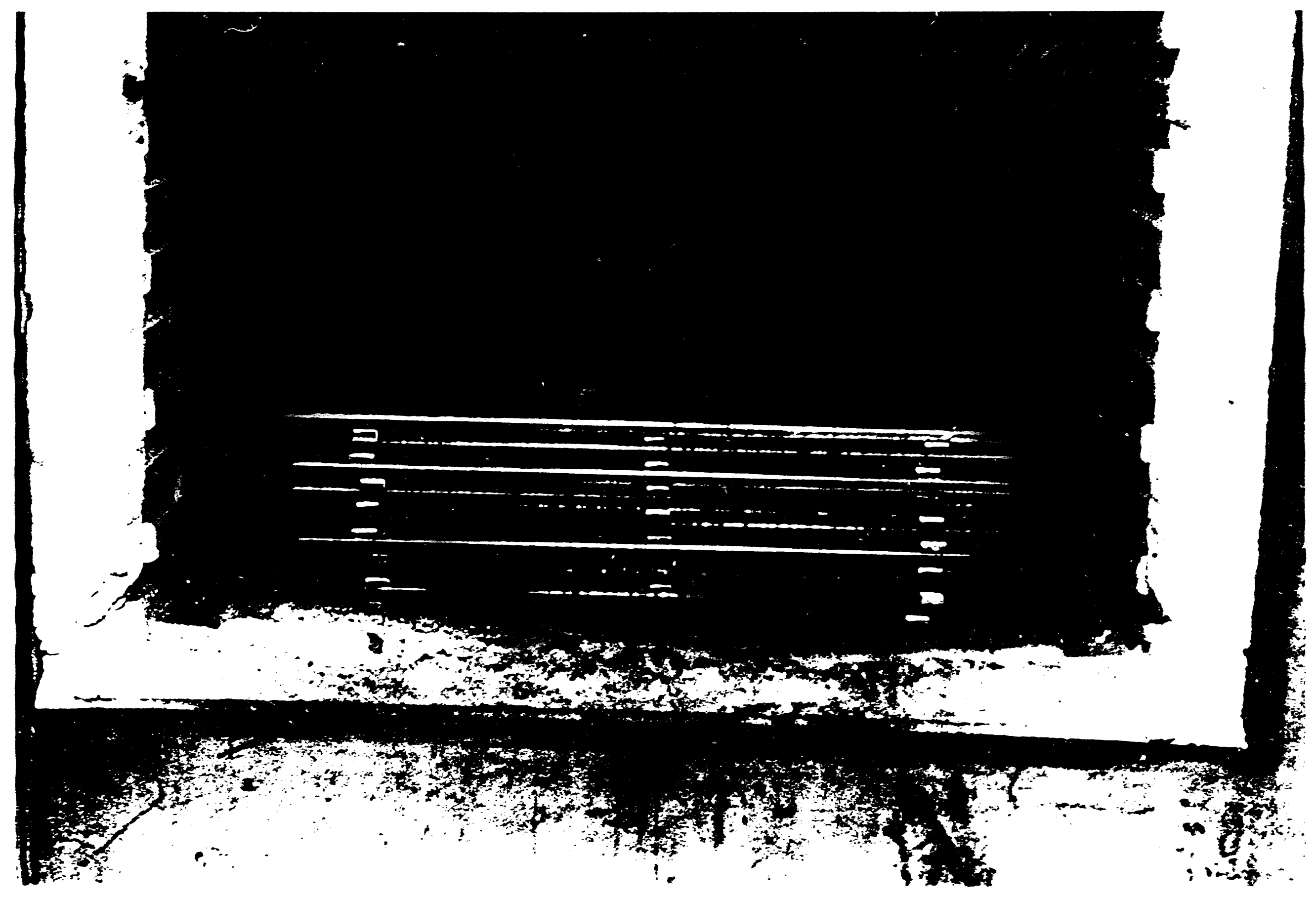

Figure 6. Photograph of plates stacked horizontally in the oven 


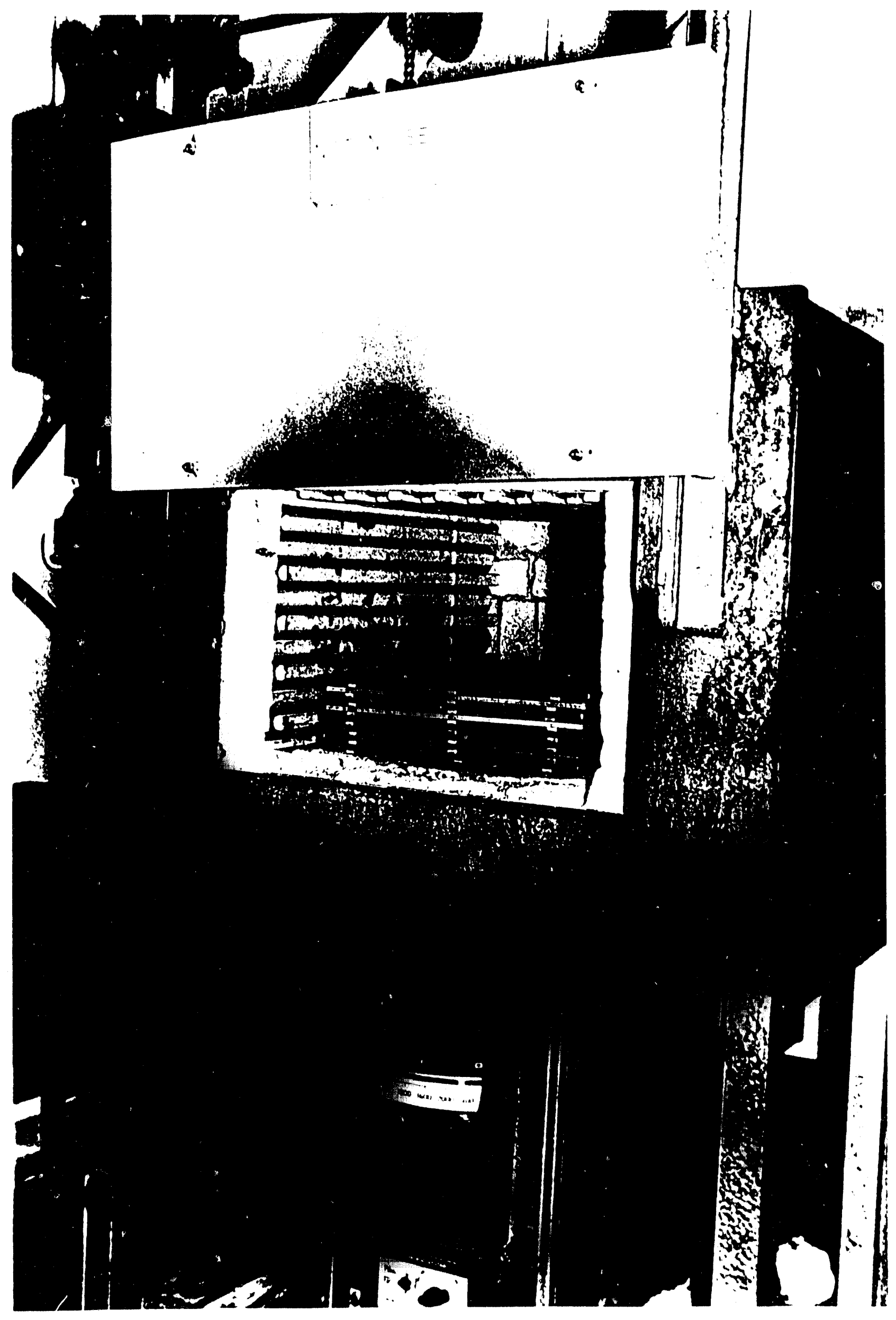




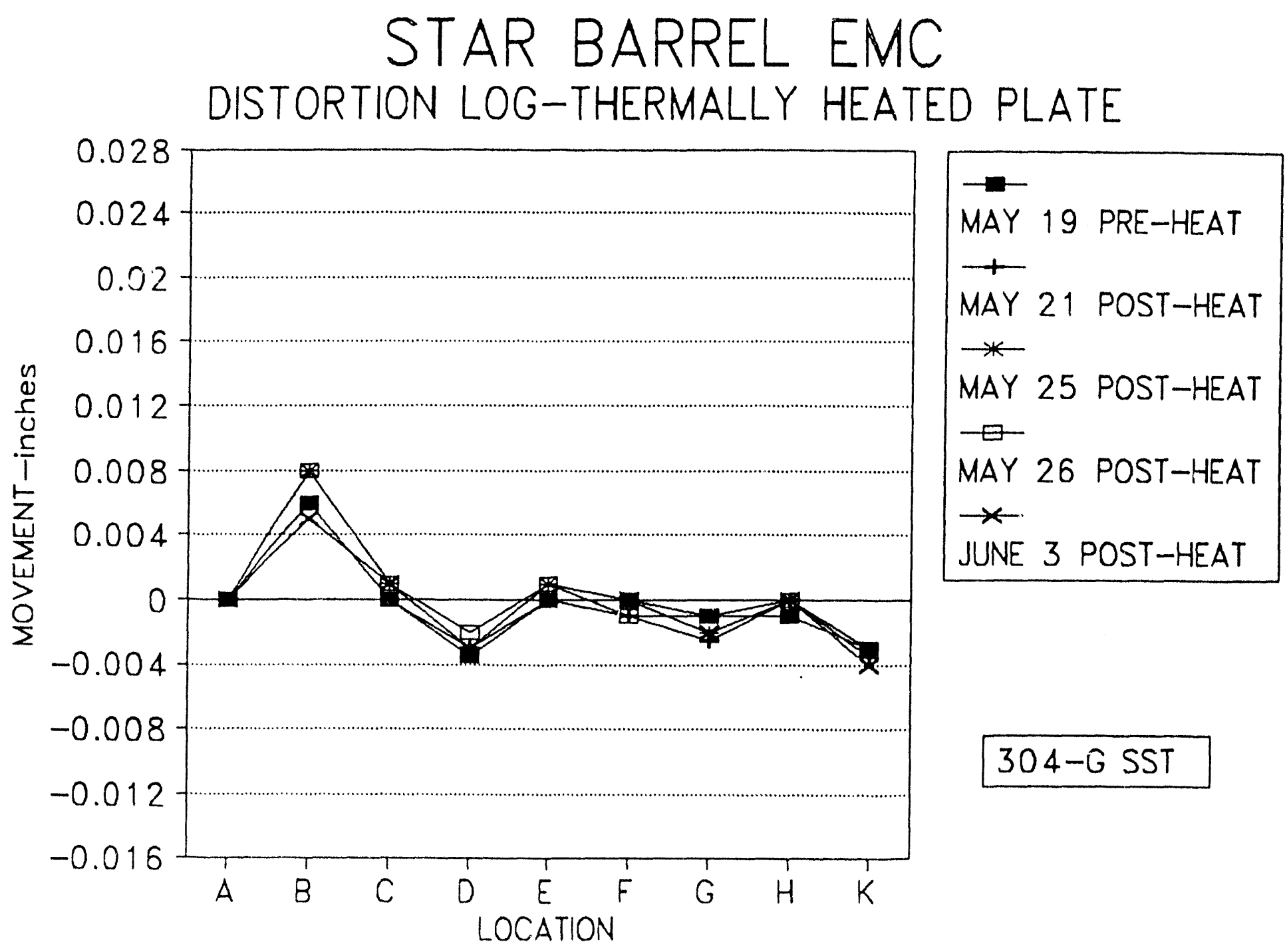

Figure 8. Type 304 stainless steel with ground surfaces. 


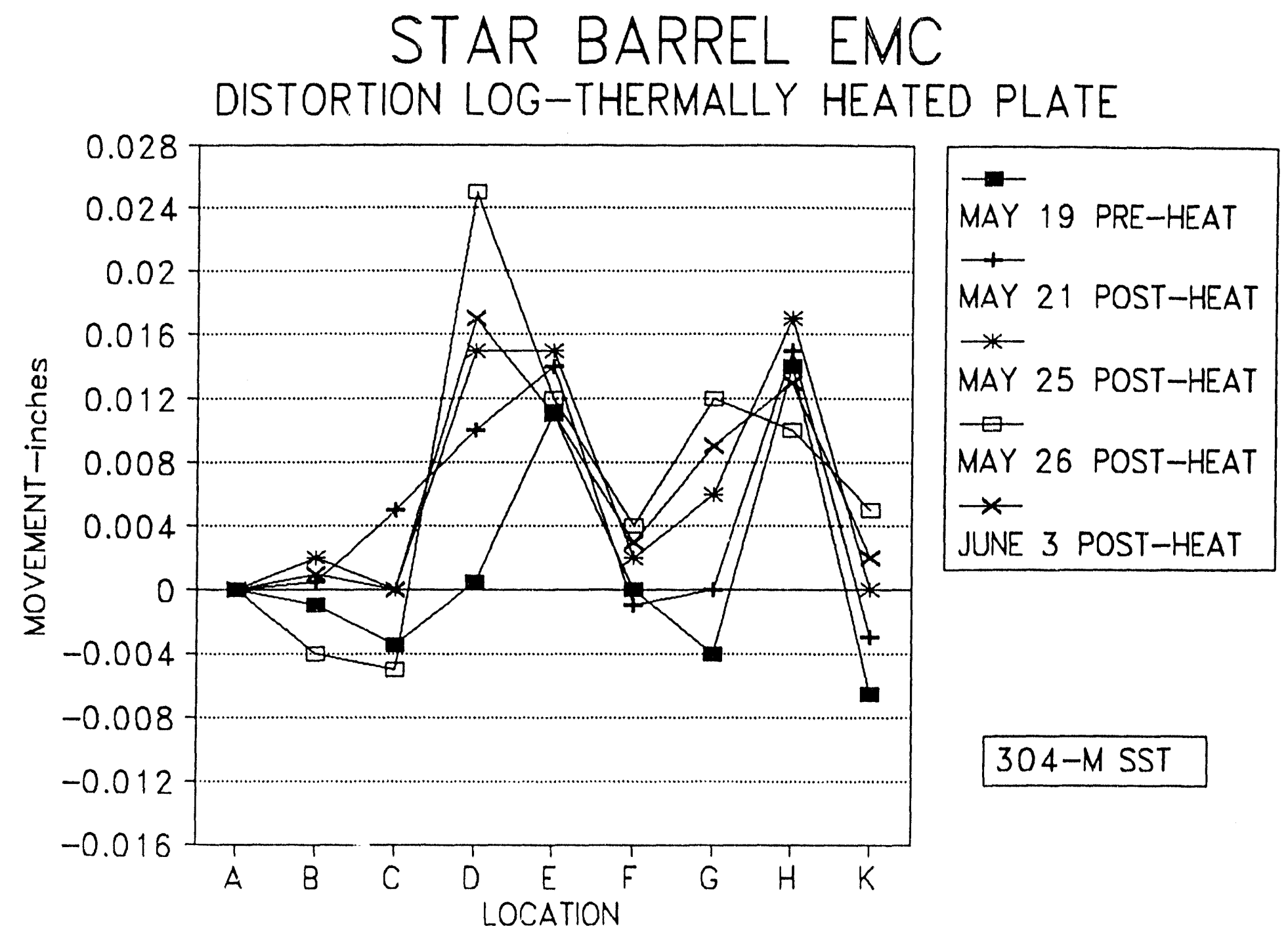

Figure 9. Type 304 stainless steel with machined surfaces. 


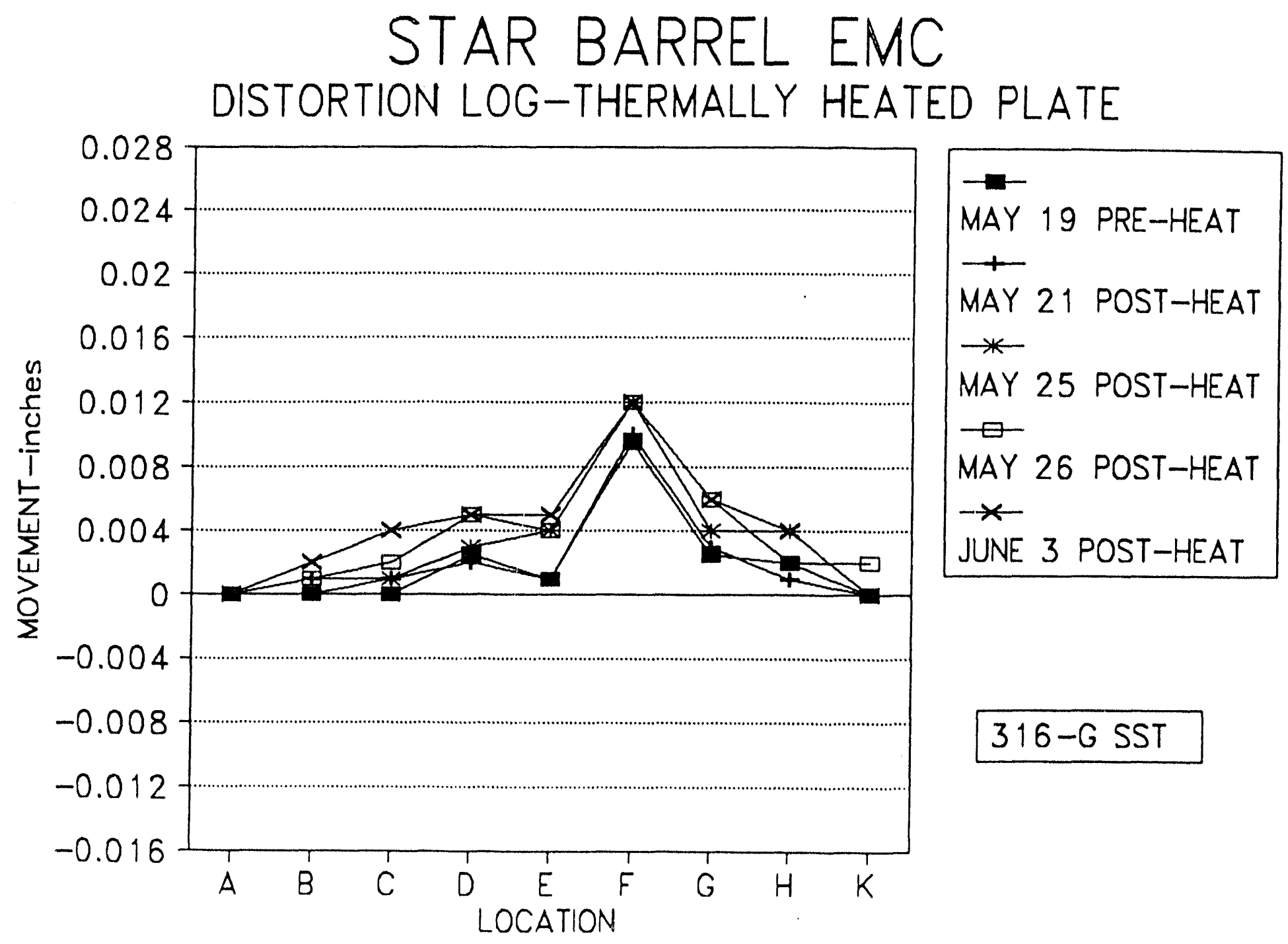

Figure 10. Type 316 stainless steel with ground surfaces. 


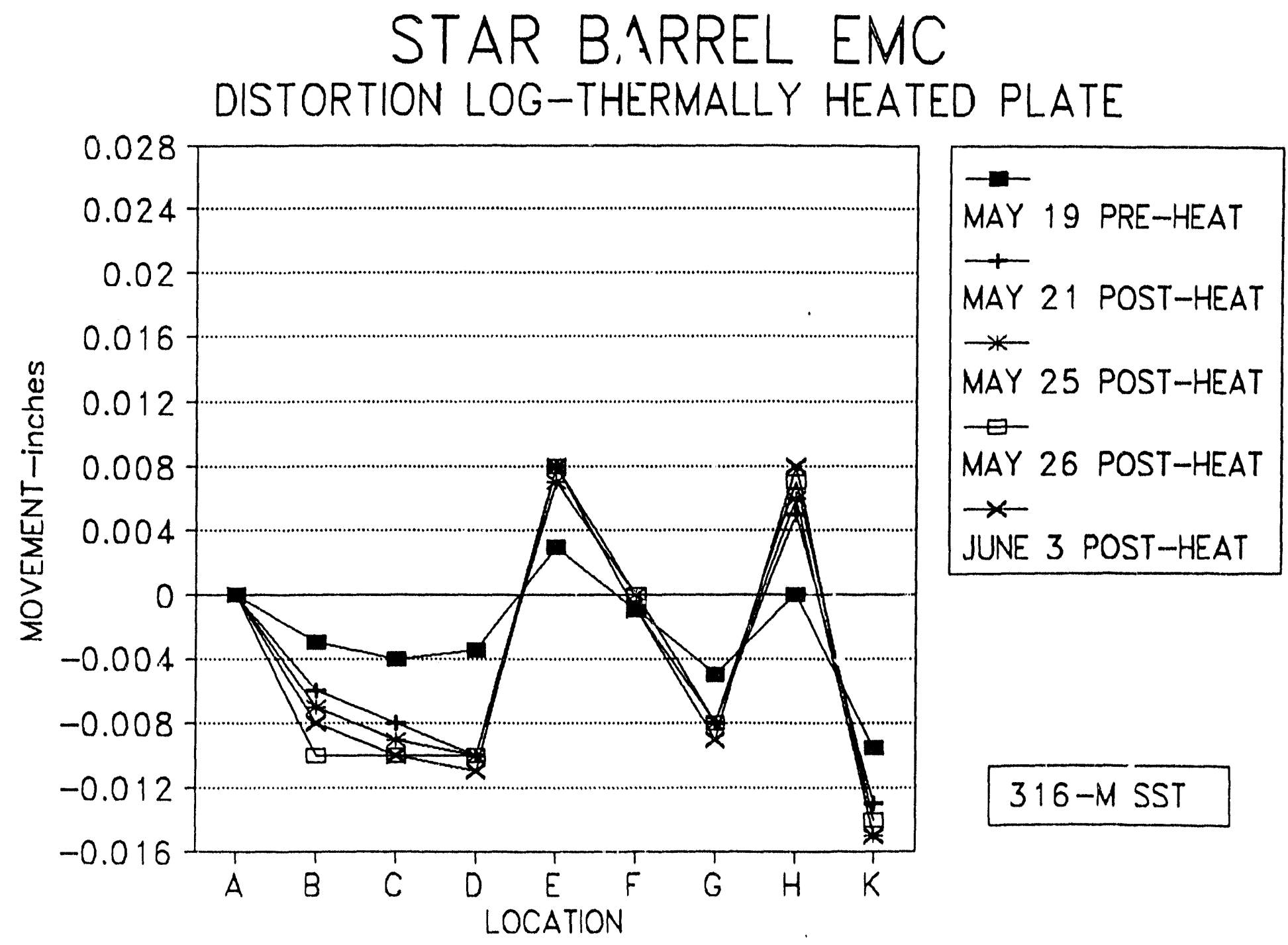

Figure 11. Type 316 stainless steel with machined surfaces. 


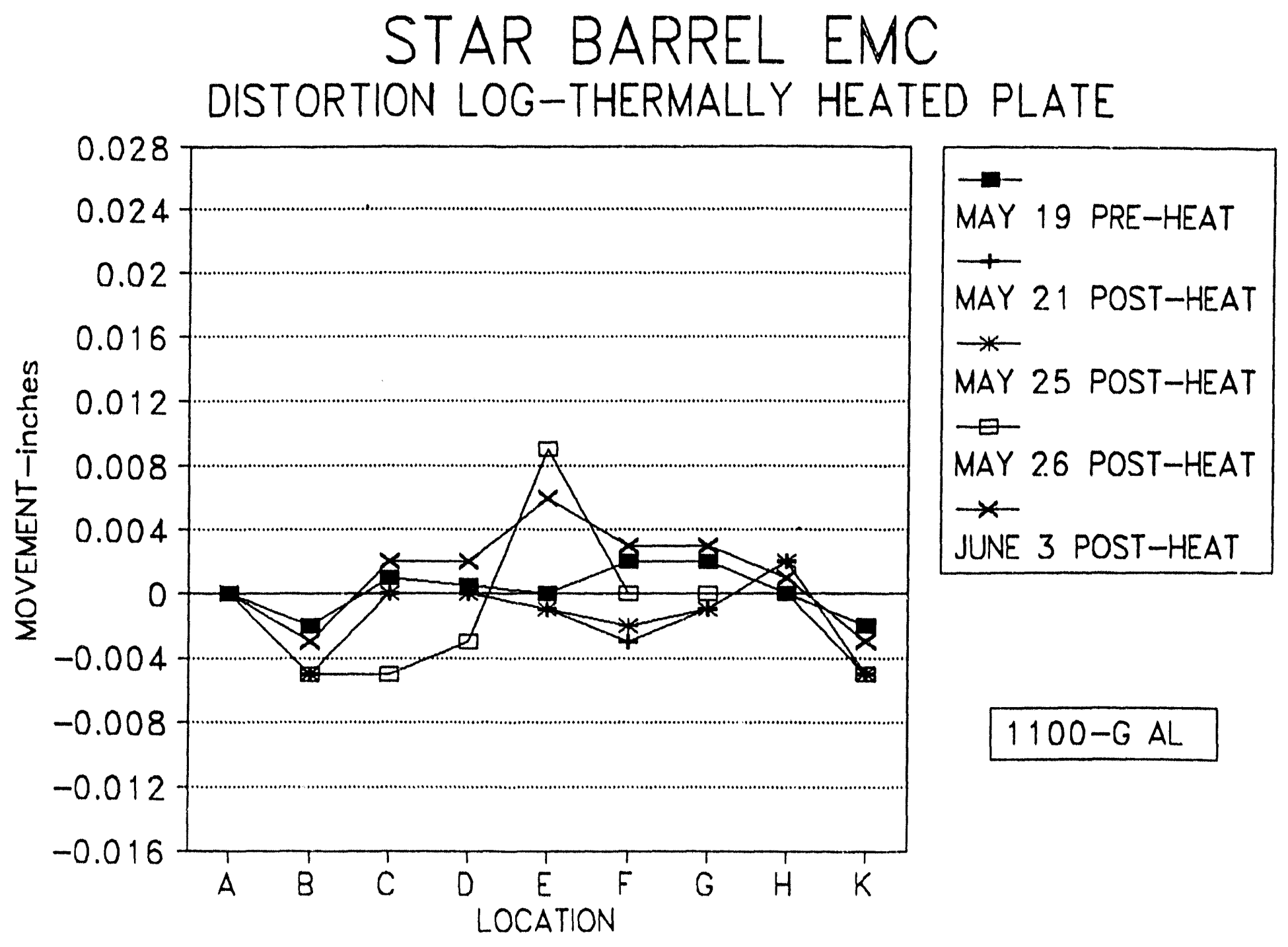

Figure 12. Type 1100 aluminum with ground surfaces. 


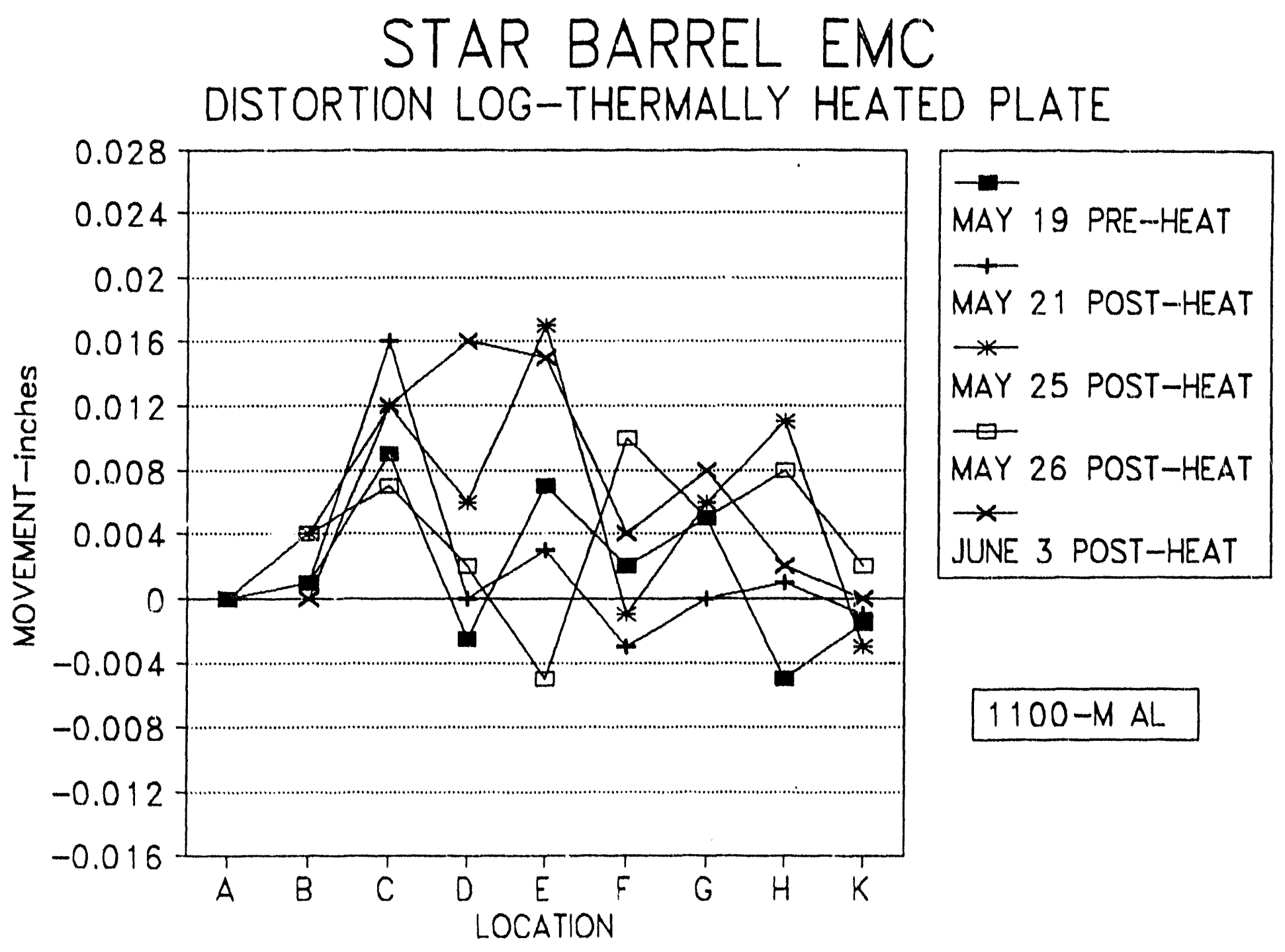

Figure 13. Type 1100 aluminum with machined surfaces. 


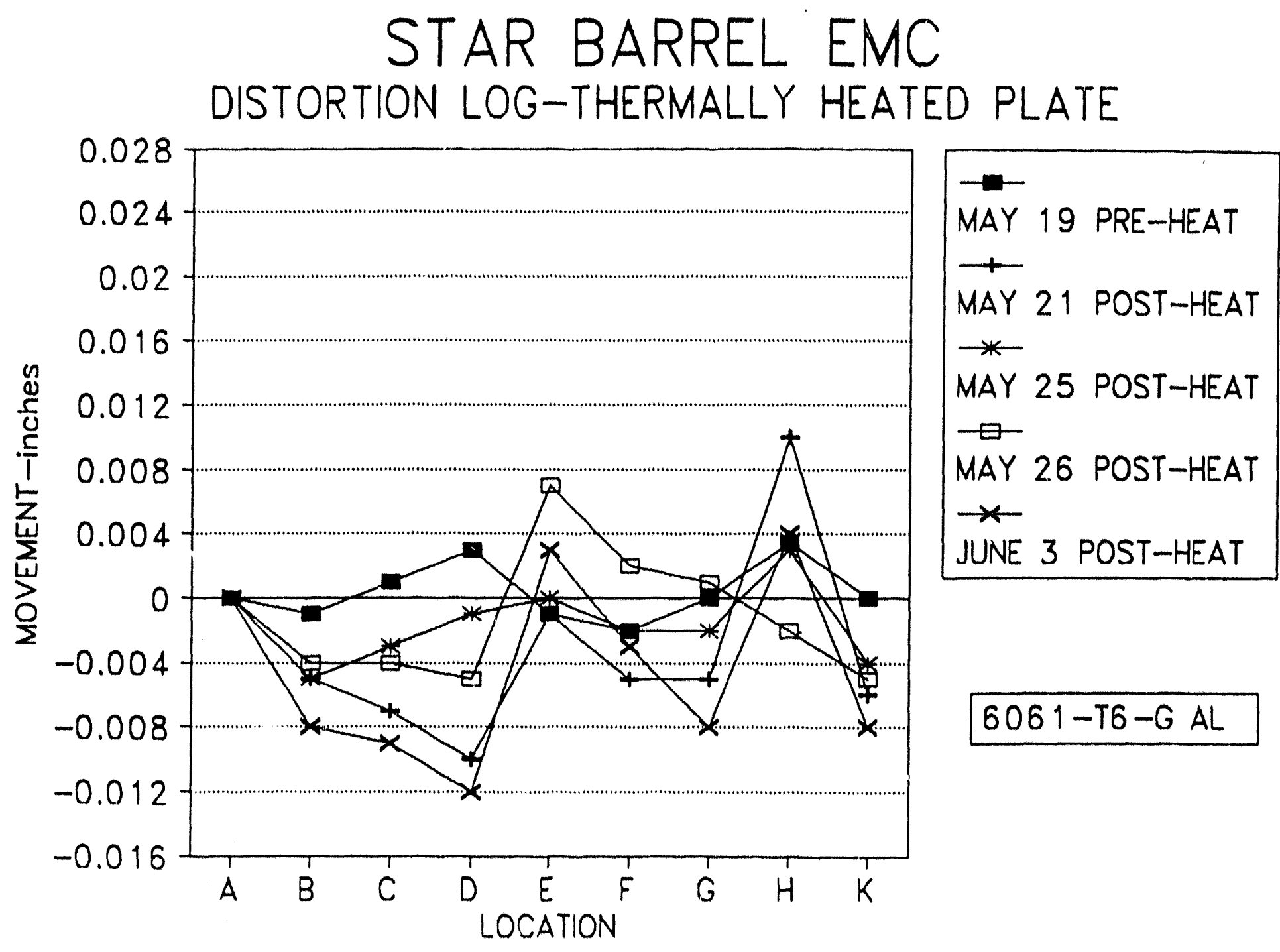

Figure 14. Type 6061-T6 aluminum with ground surfaces. 


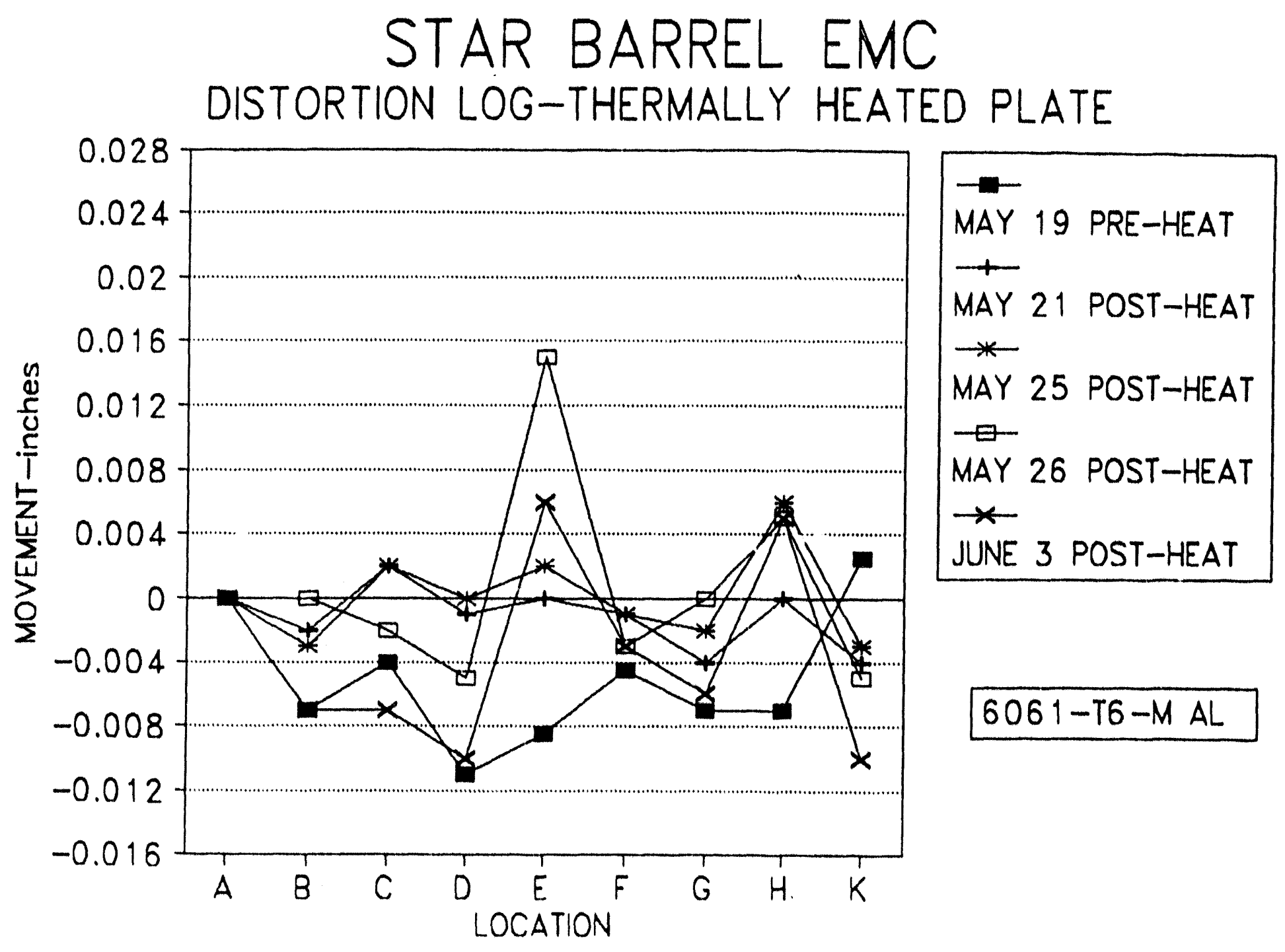

Figure 15. Type 6061-T6 aluminum with machined surfaces. 

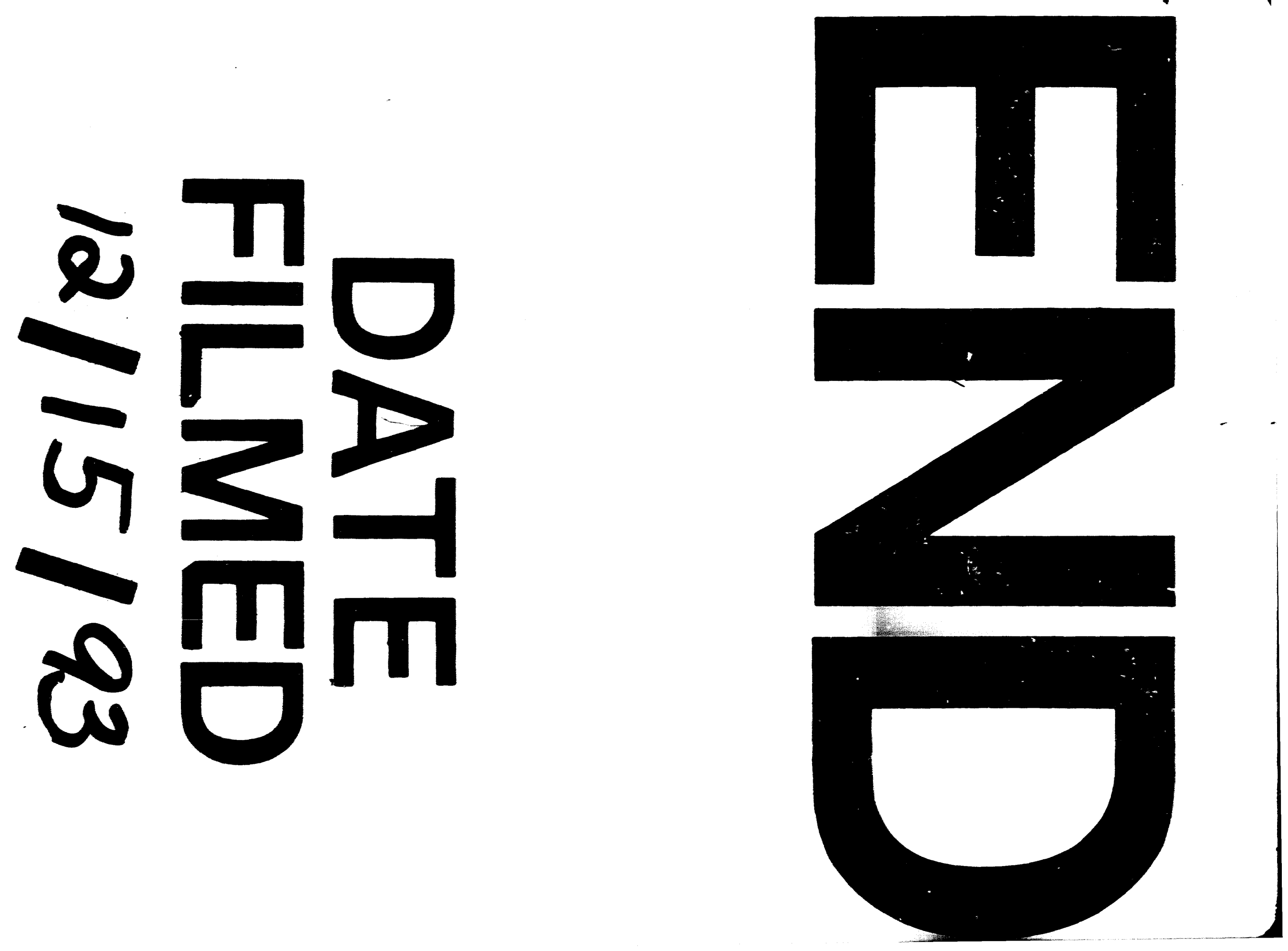
